\title{
Sociocultural genome of law: digital transformation
}

\author{
Vlada Lukyanova* \\ ILCL under the Government of the Russian Federation, Department of Legal Analysis and Sociology of Law, B. Cheremushkinskaya \\ street, bldg. 34, 117218, Moscow, Russian Federation
}

\begin{abstract}
The article studies key elements of the sociocultural genome of law by analyzing the changes it has undergone under the influence of digitalization. The author highlights the following among the main directions of this influence: change in the parties eligible for a legal relationship, since "digital personalities" have recently become one of them, and their activity is on the rise; emergence of algorithmdriven quasi-legislative regulatory institutions (regulatory institutions that are based on a programming code instead of a legal norm); change in the scope of legal regulation and the structure of law. Emergence of quasi-legislative regulatory institutions that are based on a programming code has a no lesser influence on the sociocultural genome. That is why the article especially focuses on the comparative analysis of attributive traits of a legal norm and of a programming code as the "building material" for creating relevant social relationships regulators. A conclusion is drawn that the ever-intensifying use of information technology in various spheres leads to substantial change in the sociocultural genome of law and, subsequently, to change in the composition of the existing model of social regulation.
\end{abstract}

\section{Introduction}

Law is one of the most important social regulators. It forms a "field of opportunities" within which the activities of people are carried out, predetermines the legitimacy of one or another of its types.

However, today the role and place of legal regulators in the life of a person and society is gradually changing. This is due, in particular, to the high intensity of digitalization processes in various spheres of society: the provision of state and municipal services, the implementation of control and supervisory activities, and the performance of the functions assigned to them by public authorities are transferred to digital. Digital technologies are increasingly being used in education and medicine. They (technologies) are increasingly used by ordinary citizens.

Moreover, in the Russian Federation, according to the Decree of the President of the Russian Federation of July 21, 2020 No. 474 "On the national development goals of the Russian Federation for the period up to 2030", the share of mass socially significant services available in electronic form by 2030 should reach $95 \%$. Also, this document provides for an increase in the share of households that are provided with the possibility of broadband access to the information and telecommunications network of the Internet, up to $97 \%$ and the achievement of "digital maturity" of key sectors of the economy and social sphere, including healthcare and education, as well as public administration.

Here one can also mention the development of mechanisms of "electronic democracy", the "invasion" of digital technologies in the field of lawmaking, law enforcement and legal proceedings, etc.

The law cannot ignore such changes. And therefore, today it recognizes the legal force of virtual actions, fixes the features of transactions carried out using digital technologies, establishes responsibility for the commission of crimes and offenses using information and telecommunication networks (including the Internet). The influence of digital technologies on law is so great that it affects not only external manifestations, but also the socio-cultural genome of law, determines its changes. Law is one of the most important social regulators. It creates a "field of opportunity" for people to act in, and makes certain activities lawful and legitimate.

\section{Sociocultural genome of modern law: some characteristics}

As you know, the term "genome" was proposed by the German botanist G. Winkler in 1920 to designate a haploid set of chromosomes that characterize a biological species. In molecular genetics, the genome is a set of sequences of nucleotides in DNA molecules (in some viruses, in RNA), characteristic of each cell of individuals of a given species; it contains both coding sequences (genes) and non-coding genetic elements. In other words, it is the structural features of the genome, combinations of its constituent coding sequences and non-coding elements that form and consolidate the characteristic features (traits) of each biological species. 
In the process of vital activity of the organism, the structure of the genome of its individual cells can change-spontaneously or under the influence of external factors. Some of these changes are fixed in generations (mutations). The emergence and fixation of mutations lead to the fact that the genome of each individual is characterized by its own DNA nucleotide sequence, which distinguishes it from the genome of another individual (these differences characterize the variability of the genome of a given biological species). In addition, every genetically integral group of individuals (population) has statistically described features of the genome [1].

With a certain degree of conventionality, these ideas can be applied to the legal sphere. Law as a phenomenon has the same essence in all corners of the globe. In its most general form, this essence, the structure of law, specific means and methods of influencing social relations, the peculiarities of interaction with other social regulators are predetermined by several "coding elements". For the purposes of this study, the following postulates are of particular importance:

- law is a set (system) of generally binding, stateguaranteed rules of conduct that govern social relations. Compliance with these rules is ensured by the coercive force of the state, the application of legal sanctions in case of their violation;

- the law is created by people and for people;

- it always appeals to the will and mind of a person, "to the will of a rational being, capable of setting goals for himself and striving to achieve them" [2, p. 85].

- legal regulation is of a one-sided and strongwilled nature, i.e. the norms of law are adopted or sanctioned by the state and cannot arise and exist without a legislative decision of the state power;

- the sphere of legal regulation is "a set of relations that develop between people, accompanying life facts and circumstances that objectively can and, from the point of view of modern tasks of the state, should be or have already been subjected to legal regulation" [3, p. 64].

However, the conditions of different countries, their socio-cultural, economic, political reality, traditions, mentality of peoples are not the same. Therefore, the essence of law manifests itself in different ways in different legal families and in national legal systems, in their inherent features. Among the most significant aspects of the legal nature of the legal family, scientists mention the method of normative legal consolidation and the paradigm of the practical implementation of the idea of justice [4, p. 99].

For example, the main features of the RomanoGermanic legal family, to which Russian law can also be attributed, in the form as we know them now, were formed in the era of modernity. The right of modernity came to the historical scene together with new science and technology, together with "a man of a new typesecular-who believes in reason more than in religion" [5].

This person appeared in the form of a free individuality, an autonomous personality, which can be included in various social communities and has equal rights with other autonomous individuals of the same kind [6, p. 9]. Accordingly, the law was built on the principle of equality of responsible individuals who appear before the law in their personal capacity, and not as members of various ethnic, confessional and social groups.

The paradigm of the practical implementation of the idea of justice, characteristic of modern law, is based on two "whales". The first is the idea of equality of everyone before the law and the type of legal equality based on it. "The law is unforgiving. And it is desirable because of this equalizing everyone relentlessness. The law is ready to punish both the rich and the poor. The norms of the law are not oral, but written. The special class of people gives the written law an allencompassing completeness.

Procedures are strictly regulated to separate the guilty from the innocent. These procedures are known to society and accepted by society. Institutions monitor the implementation of the procedures. Institutions are built in such a way as to exclude procedural errors as much as possible" [7, p. 21-22].

The second is the understanding of the conventionality of law, which is perceived both as a measure of formal equality and as a measure of freedom: if a law does not provide formal equality, then this is a non-legal law. If the law excessively, to a greater extent than is necessary for the freedom and security of all members of society, restricts the freedom of the individual, then this is a non-legal law [8].

The main way of securing legal prescriptions is a regulatory legal act.

The "coding elements" reflecting the characteristic features of modern law are:

- structure of law. Modern law is subdivided into branches of law, in the center of each of which, as a rule, there is a corresponding code; in some cases, subbranches are distinguished. The next element of the structure is the institutions of law, and the "elementary particle" of legal reality is the rule of law. The latter, in turn, is understood as "a generally binding command, expressed in the form of an imperative prescription, regulating social relations and having the following specific features: normativeness, consistency, general obligation, formal certainty and representative-binding character" $[9$, p. 50];

- the written and publicly available nature of the official documents in force in the state that establish or authorize the rules of law;

- close connection and interdependence of all existing norms, their indissoluble unity. Some norms can develop, supplement and concretize others, narrow or expand their meaning and scope, establish exceptions to general rules, etc.

However, today many "coding elements" of the socio-cultural genome of law, thanks to which law serves as a social regulator, are under pressure, "blurred" under the influence of digitalization processes in various spheres of society. 


\section{Changes in the socio-cultural genome of law in modern conditions}

It was noted above that digital technologies are more and more actively involving every person, since these technologies are easy access to information and improved communication, convenience of travel and improved entertainment, comfortable interaction with public authorities and the ability to find friends and acquaintances with whom we have been in contact and whom we have lost many years, if not decades, ago. However, digitalization processes, like all manifestations-or products-of scientific and technological progress have a dialectical nature. And by virtue of this nature, the intensive development of these processes entails not only benefits, but also costs. In particular, digital technologies negatively affect the mental ecology of humans and society. It is no coincidence that the World Health Organization, developing a new version of the International Statistical Classification of Diseases and Related Health Problems (ICD-11), has included in its section on mental, behavioral and developmental disorders of the nervous system, a new phenomenon-play disorder-which is associated with excessive hobby of a person for computer and video games. Among other results of the negative impact of digital technologies on humans, researchers name such phenomena as:

— information overload of a person [10], which is due to a constant increase in the amount of information they receive (useful, useless, harmful) in combination with a decrease in the auditory and fake resistance of the communication systems of modern society and the society itself;

- displacement of mythical and historical traditions that constitute the identity of collective subjects, elements of "instrumental rationality" and mass culture;

- gradual transformation of the modern "book culture" into a "screen culture", as a result of which the worldview is replaced by a world perception, and a person moves from the rational ideal of cognition to the aesthetic one [11];

- blurring of the boundaries between fiction and reality and the exacerbation of the problem of the authenticity and integrity of a person's personal identity. Each individual, being in one or several "realities" (social networks, computer games, etc.) at the same time, independently forms their identity in relation to each "reality", replacing "deep self-identification of the individual with self-presentation, and beingness with the appearance" [12];

— the ability of third parties to manipulate the digital fingerprint of a person, including posthumously. Today, almost everyone leaves their digital footprint on the Internet. And this trace, which is far from always positive, continues to "live" in the information space even after the biological death of a person. Since not all people want this, the "right to be forgotten" was enshrined in the legislation of a number of states, including the Russian Federation. Some countries have gone further. For example, in France, back in 2016, the
Law "On the Digital Republic" was adopted, which, in particular, establishes the human right to "digital death". Under this law, as in the case of an ordinary will, a person has the right to comply with the online service providers or proxies of his will regarding the future fate of personal information published online, and after death. One more aspect of manipulating the digital footprint of a person is touched upon in the book by $\mathrm{K}$. Eichorn "The End of Oblivion" [13]. It also suggests that the overall problem of digital traces of an individual is far from being resolved;

- a possible change in the biological nature of a person predicted by researchers $[14,6]$, replacing a person as a being of biosocial nature with "technology interspersed with living things" (at the first stage: "alive with interspersing technology").

Thus:

- the rapid development of information technologies, the increasingly active digitalization of various spheres of human society's life entail the "blurring" of the collective, individual and personal identity of a person;

- the ever-increasing volume of information flows, which a modern person is forced to perceive and process, gives rise to difficulties in synthesizing data and forming a holistic worldview. And if there is no worldview, what kind of legal consciousness can there be? Enforcement? Legal culture?

These and other changes are gradually transforming the sociocultural genome of law. In our opinion, the most significant are the following transformations.

1) the idea of persons "for whom the state recognizes the ability to be carriers of subjective rights and legal obligations" [15, p. 607]. In modern law, the subject and goal of legal relations is a person, "a living person, with his natural needs, with his real inclinations" [2, p. 63]. However, as a result of the destruction under the influence of information technologies of his collective, individual and personal identity, a person is unable to form a holistic worldview. As a result, a person loses his position as a subject of law.

At the same time, new-digital-entities begin to play an increasingly active role in the life of society. It is so active that in 2017 the European Parliament, in its resolution, together with the recommendations of the Commission on Civil Law on Robotics, outlined the need to determine a special legal status for robots in the long term, so that at least the most complex autonomous robots could be endowed with the status of electronic persons who are responsible for their actions and may make independent decisions or otherwise independently interact with third parties.

The Russian state approaches these issues with a more restrained attitude. This is evidenced by the provisions of paragraphs "a" of clause 19 of the National Strategy for the Development of Artificial Intelligence for the Period up to 2030, approved by Decree of the President of the Russian Federation No. 490 dated October 10, 2019, according to which one of the basic principles for the development and use of artificial intelligence technologies, compliance with which is mandatory in the implementation of the specified 
strategy is to protect human rights and freedoms: ensuring the protection of human rights and freedoms guaranteed by Russian and international legislation, including the right to work, and providing citizens with the opportunity to acquire knowledge and acquire skills for successful adaptation to the digital economy.

Nevertheless, some researchers have already rushed to ascertain the death of the subject of law [16]. Others $[17,18]$ tend to the need to recognize digital entities and inanimate things as a subject of law, paying increasing attention to the study of the legal personality of artificial intelligence units, robots, the responsibility of their developers, manufacturers, operators and the robots themselves. The issues of endowing artificial intelligence units with certain rights, in particular, the right to function, to self-study, etc., as well as the extension of human rights to them (in their constitutional sense) are discussed.

Replacement of a normative legal act as a way of securing legal prescriptions by quasi-legal regulators, the basis of which is the program code. By comparing the attributive features of the rule of law and the program code (Table 1), we note that the latter rigidly determines the algorithm of action of the subject of regulated relations, without assuming the possibility of discretion, and is not formally defined. Accordingly, the use of quasi-legal regulators excludes any discretion in the regulation of social relations.

Table 1. Norm of law vs Program code

\begin{tabular}{|l|c|}
\hline Norm of law & Program code \\
\hline $\begin{array}{l}\text { Set out in everyday } \\
\text { language, should be simple } \\
\text { and accessible, but without } \\
\text { prejudice to the } \\
\text { completeness and clarity of } \\
\text { regulations }\end{array}$ & $\begin{array}{c}\text { Expounded in } \\
\text { programming language or } \\
\text { markup language }\end{array}$ \\
\hline $\begin{array}{l}\text { Is formally defined, i.e. } \\
\text { expressed in writing in } \\
\text { official documents }\end{array}$ & $\begin{array}{c}\text { The program operates on } \\
\text { the principle of a "black } \\
\text { box }\end{array}$ \\
\hline $\begin{array}{l}\text { Appeals to the will and } \\
\text { mind of man }\end{array}$ & $\begin{array}{c}\text { Rigidly defines the } \\
\text { algorithm of action, does } \\
\text { not imply the possibility of } \\
\text { discretion }\end{array}$ \\
\hline
\end{tabular}

Currently, some researchers note that regulatory legal acts and "familiar legal texts are inaccessible and irrelevant for most people" [19, p. 49]. Quasi-legal regulators based on program code will be out of reach of most people, including lawyers, to a much greater extent. After all, the rule of law is stated in ordinary language, and any legislative and other normative legal acts, in particular, acts affecting the rights, freedoms and duties of a person and a citizen, cannot be applied if they are not officially published for general information. This is directly indicated by Part 3 of Art. 15 of the Constitution of the Russian Federation. In turn, the program code is written in a special language-a programming language - that is accessible only to a fairly narrow circle of people with special knowledge. At the same time, all people who will operate such quasi-legal regulators or comply with their instructions, unless they are IT specialists, will not deal with the software code itself and the regulatory instructions set out by it, but only with the "human-friendly" software shell. A citizen will not be able to trace the development of a normative prescription and measures of state coercion that ensure its implementation within the framework of one or several "digital acts" (quasi-legal regulators), which will make it practically impossible to appeal them. Thus, under the "pressure" of digital technologies, the very "coding elements" of the sociocultural genome of modern law, which allowed it to take a dominant position in the system of social regulators of social relations, are "blurred".

One more aspect should be noted: the law-making (rule-making) process is becoming more and more technologized. In these conditions, there are those who postulate the need to abandon the "rigid format of traditional legal texts" and replace them with a digital, machine-readable law, which "will allow the application of legal norms with the help of algorithms and without human intervention" [20, pp. 146, 147]. True, it is not clear whether in this case it is possible to speak about legal norms and legal regulators. But another thing is clear: with this approach, a person loses the properties of not only the subject of law, but also the subject of rulemaking activity.

In general, their increasingly widespread use leads to the destruction of one of the key "coding elements" not even the law of modernity, but the law "in general"—its appeal to the will and reason of man.

1) change in the scope of legal regulation. The emergence of new-"digital"—subjects of law entails a change in the sphere of legal regulation, which becomes multi-meaningful due to the inclusion of atypical social relations, including those that practically exclude direct human participation. Moreover, in the process of "digital modernization" within the sphere of legal regulation "not only new relations arise, but its structure changes significantly, the existing connections are modified. It is formed by both typical and atypical social relations for it from the point of view of the subject composition, objects and environment of existence" [21, pp. 112-113]. Another characteristic feature of the impact of digitalization on the sphere of legal regulation is the appearance in its structure of public relations, which should, but for objective reasons cannot be regulated by law in the required volume at present.

2) changing the structure of law. It was already mentioned above about the gradual replacement of the rule of law by quasi-legal regulators based on program code. However, this change is not the only one in this area. Along with branches and institutions characteristic of modern law, normative arrays with unusual properties appear in the structure of law, which researchers have designated as "cyclical legal arrays" [21, pp. 117-126]. An attributive feature of such arrays containing "crosssectoral" legal norms is that they do not show a tendency towards isolation, like industries, but demonstrate the 
ability to permeate all or most of the elements of the legal system. They are introduced into the established elements (branches, institutions) of the legal system, determine their content, functioning, and the direction of further development.

Changes in the field of law enforcement. Representatives of legal science have repeatedly drawn attention to how the expansion of digitalization in various spheres of society affects the processes of law enforcement. Let us touch on just one aspect. As shown above, the increasingly widespread use of digital technologies is changing the mentality of a person acting as a subject of law, their legal consciousness and, consequently, the nature of activities related to the implementation of legal norms. This allows some researchers to predict the formation of "an individual legal order, when the subject will be able to partially determine their legal status, to assume obligations to comply with regulatory norms both in the virtual space and outside it" [22, p. 206].

However, the rule of law is a state of public relations, programmed by law, based on law and legality, the organization of public life, reflecting the qualitative state of public relations at a certain stage. This is an order where the relationship between bodies, organizations and individual citizens is clearly defined by law, secured and protected by state power. In turn, law, the law today is a universal regulator, a criterion for correlating the actions of an individual with the requirements of society, due to the characteristics of the environment and lifestyle of its members.

Therefore, the formation of "individual legal orders", the recognition of the permissibility of their diversity means an increase in the fragmentation of a single legal space and at the same time the destruction of the identity of national legal order, leading to their leveling. Ultimately, this leads to the loss by law of its properties as a universal regulator of social relations, an instrument for the practical implementation of the idea of justice as the idea of equality of everyone before the law. The basic idea of modern law is "blurred": the equality of everyone before the law, which is the same for everyone.

\section{Conclusion}

The analysis shows that law, as a universal regulator, is part of the ongoing socio-economic transformations, acts not only as an instrument, but also as an object that demonstrates the dynamics of its various aspects. Moreover, the impact of transformations caused by the accelerated development of digital technologies is so great that not only the image of law and its regulatory potential, but also its socio-cultural genome undergoes changes. The law loses the properties of a social regulator created by "people and for people".

Under these conditions, one cannot but agree with those researchers [21] who predict a change in the mechanism of legal formation and the composition of the existing model of social regulation, correction of the boundaries of well-known social regulators and the formation of a niche in it, which will be occupied by the program code. However, it is obvious that the emergence of quasi-legal regulators, instruments and mechanisms of legal regulation based on the software code, like all digitalization, carries both benefits and costs. And in order to maximize the former and eliminate the latter, it is necessary to reverse the tendency to dehumanize law, and to return the central place in legal discourse to man.

\section{References}

1. N.K. Yankovsky, Genome, in: Great Russian Encyclopedia. Volume 6 (Moscow, 2006) pp. 565566)

2. G.F. Shershenevich, General theory of law: Textbook. In 2 volumes. Volume 1. Issue 1. (Publishing House "Legal College of Moscow State University", Moscow, 1995)

3. V.V. Lazarev, Determination of the scope of legal regulation, Jurisprudence, 5, 64-71 (1980)

4. A.V. Filonov, Legal system of the Russian Federation in the Romano-Germanic legal family: general and special (comparative legal aspect), Scientific notes of the Crimean Federal University named after V. I. Vernadsky. Legal sciences, 1 (2020)

5. V.D. Zorkin, Law of the modern era, Rossiyskaya Gazeta (2010, 25 June)

6. V.S. Stepin, Modern civilizational crises and the problem of new development strategies: scientific publication (Moscow, 2018) 28 p.

7. V.D. Zorkin, Law in the context of global changes: monograph (Norma, Moscow, 2013)

8. V.S. Nersesyants, Philosophy of law: libertarian legal concept, Problems of Philosophy, 3, 3-15 (2002)

9. S.V. Boshno, Norm of law: concepts, properties, classification and structure, Law and modern states, 4 (2014)

10. V.Yu. Lukyanova, On the issue of information rights of citizens, in: Philosophy of Science and Technology in Russia: Challenges of Information Technology: a collection of scientific articles (Min. Edu. Sci. of the Russian Federation, Vologda State University, Vologda, 2017) pp. 171-175.

11. A.A. Morgunov, Homo informaticus as a heuristic model, Bulletin of SamSU, 1(102), 157-163 (2013)

12. E.D. Dryaeva, Identity transformation in modern communicative environments: abstract of candidate dissertation (Moscow, 2016) $22 \mathrm{p}$.

13. K. Eichhorn, The End of Forgetting: Growing Up With Social Media (Cambridge, MA and London, England: Harvard University Press, 2019). 180 p.

14. V.A. Kutyrev, Culture and technology: the struggle of the worlds (Progress-Tradition, Moscow, 2001) $238 \mathrm{p}$.

15. M.N. Marchenko, Problems of the general theory of state and law: textbook. In 2 volumes. Vol. 2. Law, 
$2^{\text {nd }}$ ed. (TK Welby: Publishing house "Prospect", Moscow, 2010) 744 p.

16. V.I. Pavlov, From classical to non-classical legal discourse. Essays on the general theory and philosophy of law: monograph (Acad. Ministry of Internal Affairs, Minsk, 2011) pp. 283-291.

17. Yu.A. Tikhomirov, S.B. Nanba (eds.), Legal concept of robotization: monograph (Prospect, Moscow, 2019) $240 \mathrm{p}$.

18. Yu.A. Tikhomirov, S.B. Nanba, Robotization: dynamics of legal regulation, Bulletin of St. Petersburg University. Law, 11(3), 532-549 (2020)

19. D. Howes, e-Legislation: Law-Making in the Digital Age, McGill Law Journal, 47, 39-57 (2001)

20. D.A. Pashentsev, Lexical and semantic features of the language of lawmaking in the context of digitalization, in: The language of lawmaking in the context of digitalization of public relations: a collection of scientific works (D.A. Pashentsev, M.V. Zaloilo, eds.) (Institute of Legislation and Comparative Law under the Government of the Russian Federation, INFRA-M, Moscow, 2019). pp. 143-148.

21. T.Ya. Khabrieva, N.N. Chernogor, The future of law. The legacy of Academician V.S. Stepin and legal science (Russian Academy of Sciences; Institute of Legislation and Comparative Law under the Government of the Russian Federation; INFRAM, Moscow, 2021). 176 p.

22. M.V. Zaloilo, D.A. Pashentsev, National law and order of Russia in the context of digitalization, Bulletin of St. Petersburg University. Law, 10(2), 196-209 (2019) 